\title{
Impact of Traditional Education and Tablet-Assisted Education on Students: A Comparative Analysis
}

\author{
Banu Numan Uyal ${ }^{1}$, Elif Binboğa Yel ${ }^{1}$, Orhan Korhan ${ }^{2 *}$ \\ ${ }^{1}$ Cyprus International University, Lefkosa, CYPRUS \\ ${ }^{2}$ Industrial Engineering Department, Eastern Mediterranean University, Gazimagusa, CYPRUS
}

Received 13 June 2017 - Revised 24 August 2017 • Accepted 23 September 2017

\begin{abstract}
With the recent technological advances, there is a shift from traditional education to tablet-assisted learning environment. This study compares the problems experienced by students in traditional education and tablet-assisted educational activities. The impact of traditional education on students has been discussed by a comprehensive analysis of the literature. The findings showed that the physical discomforts due to tablet-use are intensively experienced at neck, upper back, lower back, and shoulder regions, which are very similar to those experienced in traditional education. Reading and writing activities have impact on the shoulders, upper back, and the left upper arm. The developed risk assessment model has shown that both educational and extracurricular activities result in significant risk factors of physical discomfort. Analysis of the muscular activity data implied that there were significant differences among muscle groups for each respondent, which validates and verifies our risk assessment model.
\end{abstract}

Keywords: physical discomfort, risk assessment model, tablet-assisted education, traditional education

\section{INTRODUCTION}

The use of technology in classrooms has resulted in a shift from the traditional classroom setting, where the student was considered as a passive consumer of educational knowledge, to a classroom in which learners are considered active participants (Figueiredo \& Afonso, 2005; Pelgrum, 2001). In addition to the widespread Internet access, tablet-assisted systems have become more attractive to teachers as being lightweight when compared to other information communication technology (ICT) devices (Henderson \& Yeow, 2012).

It is obvious that technological advances have brought certain notable improvements in the teaching process, but there is a lack of information on the impact of these improvements. For several years, many researchers have investigated the effects of traditional education on students (Limon et al., 2004; Hedge, 2005). Also, there have been several studies conducted based on the PC-assisted education systems (Menalson, 2011; Tamim, 2015). However, there are very few studies in the literature that focus on the impact of tablet-assisted education system on the students.

This study compares the problems experienced by children and adolescents in traditional education and tabletassisted/tablet-integrated educational settings and/or activities. Yet, more research is required to investigate the impact of tablet-assisted education on children. Therefore, within this study, body regions where the discomfort feelings occur during the tablet-assisted education are identified, and the risk factors that contribute to formation of physical discomforts are investigated.

(C) Authors. Terms and conditions of Creative Commons Attribution 4.0 International (CC BY 4.0) apply. $\boldsymbol{\Delta}$ bnuyal@ciu.edu.tr $\boldsymbol{Q}$ eyel@ciu.edu.tr $\boldsymbol{\Delta}$ orhan.korhan@emu.edu.tr (*Correspondence) 


\section{Contribution of this paper to the literature}

- The purpose of this study was to analyze and compare the physical discomfort experienced in tabletassisted educational activities/environments and the physical discomfort experienced in traditional education, which is widely found in the literature.

- Therefore, this study not only discusses the findings of the effects of traditional education, but also fills an important gap in the literature with the development of a risk model, which determines the impact of tablet-assisted education on students.

- Thus, a comprehensive comparison of traditional and tablet-assisted education has been achieved as a result of this study.

\section{LITERATURE REVIEW}

When educational activities or environments are considered, it is crucial to eliminate not only the undesirable design elements of the environment or equipment, but it is also important to provide necessary medium for a better educational experience.

Limon et al. (2004) scanned risk factors for 10,000 children in traditional elementary school settings in Israel, and underlined that inappropriate chair height is one of the risk factors. Hedge (2005) also underlined that most educational environment set ups are not designed for children. When ergonomics are disregarded, it is hard to avoid developing wrong lifelong habits with regards to posture or musculoskeletal health.

Roth-Isigkeit et al. (2005) stated that $83 \%$ of a sample of 749 people composed of school-aged children and adolescents had experienced pain in the past three-month period. At the same time, $64 \%$ of these students reported musculoskeletal pain. Clinch \& Eccleston (2009) underlines the fact that children experiencing musculoskeletal pain today can be adults of future experiencing more serious problems that will possibly be a burden to the health system of their country. Ismail et al. (2009) stated that pain/discomfort at neck and shoulder were the most prevalent issues among the school children.

Mohd Azuan et al. (2010) provide that neck pain was significantly affected by overall satisfaction with furniture used in the educational environment. The results of their study imply that the most frequent musculoskeletal discomfort type in school children is the neck pain; lower and upper back pain come next.

Briggs et al. (2004) concluded that children reading from books had more flexion in head and neck regions and a greater gaze angle when compared to other IT equipment types considered, which had higher display positions.

Straker et al. (2009) performed an analysis on 24 children (10-12 years old) during an educational activity, namely, a reading and writing task, and analyzed postures of children. The tasks were performed on a desktop computer and a traditional paper-based system (book, paper and pen combination). Mean postures during reading and writing activities with traditional paper-based system were less neutral than computers (with higher display height). As far as muscle assessment is concerned, traditional paper-based IT was associated with higher muscle activity levels.

Zovkic et al. (2011) focused on computer usage in a traditional educational environment and identified wrist pain, dry throat, eye irritation, visual problems, headaches, neck and back pain as problems faced by students when they are at primary school age.

Computer screen device usage may result in a syndrome named Computer Vision Syndrome, which includes problems like headache, eyestrain, and neck/back pain (Yan et al., 2008). When school children are subject to the risk of experiencing this syndrome, it becomes a more critical issue as their musculoskeletal and vision developments are not yet complete.

Hashemi et al. (2011) underlined the effectiveness of mobile learning on the pedagogy and supported the idea of using mobile devices such as tablets as an educational tool. Greig et al. (2005), Sommerich et al. (2007), and Straker et al. (2008) claimed that there is an association between tablet usage and musculoskeletal discomfort.

The results of Kim et al. (2014) imply that prolonged use of touch screen keyboards potentially increase the risk of experiencing musculoskeletal discomfort and affect muscle groups (as a result of this static loading) in wrist and shoulder regions.

Zunjic et al. (2015) discussed the factors that affect the quality of education such as the dimensions of school furniture with respect to the students' anthropometric properties, and conclude that a comfortable working environment (air conditioning, illumination, etc.) improve the education experience in the registered environments and activities. Additionally, Woo et al. (2016) have shown that children/adolescents experienced a similar risk factor of musculoskeletal discomfort as adults when they use computer devices. 
There are scarce resources on tablet-assisted education in the literature, and none of them addresses the physical discomfort impact on the students. This research is designed uniquely to collect data from the respondents based on their user behavior and discomfort experiences during tablet-assisted education, and recalls analyses from the literature made for traditional education. Therefore, the impact of traditional and tablet-assisted education is discussed by comparing the analysis of the data collected for tablet-assisted education and the data analyzing the impact of traditional education found in the literature review.

\section{METHODOLOGY}

Within the context of this research, a two-part questionnaire were utilized to gather data from children/adolescents in public and private secondary and high schools in northern Cyprus. These are: (1) a modified version of Dutch Musculoskeletal Discomfort Questionnaire (DMQ), and (2) Student Specific Cornell Musculoskeletal Discomfort Questionnaire (SS-CMDQ).

In the first part, modified DMQ (Hildebrandt et al., 2001) was used to collect data on the children/adolescents demographic variables; attitude and habits related to tablet-use, experiences during use of those devices, and lifestyle of the respondents.

The second part consists of SS-CMDQ (Erdinç \& Ekşioğlu, 2009a \& 2009b), which is the modified version of the Cornell Musculoskeletal Discomfort Questionnaire (CMDQ) (CUergo, 1999), which was used to identify pain or discomfort frequency for the past week and check if academic activities of respondents were interrupted by any discomfort experienced.

The designed questionnaire, thus, aims to identify the risk factors involved in any type of strain experienced by respondent students who use tablets for educational purposes, the relationships (if any) between demographics of the subjects and the frequency or severity of the discomfort they experience, and the relationships (if any) between any discomfort experienced and the frequency or duration of tablet-use.

The questionnaires were filled in computer classes or in the classrooms; it took each respondent approximately 20-30 minutes to fill in a questionnaire. Two versions of questionnaires (Turkish and English version) were used because the sample consisted of students of different nationality.

The research was approved by the Scientific Research Ethics Committee (Eastern Mediterranean University, decision number 2014/04-01). In addition, this study was granted by the General Secondary Education Department of the Ministry of Education to gather data from schools in Northern Cyprus.

A sampling study has been conducted to find out the number of respondents. For this purpose, the Yamane formula (Yamane, 1967) with 95\% confidence level and 5\% sampling error was utilized. Descriptive statistics have been collected for each question available in the questionnaire. The body regions of the respondents where physical discomforts are highly experienced were identified. Pearson correlation analysis is constructed to find out (if there is) any relationship between reason of tablet-use and experience of discomfort.

In order to determine a meaningful and statistically significant relationship between experiences of strain and discomfort and tablet-use, a risk assessment model has been developed using logistic regression. As a means of avoiding the multicollinearity between independent variables that were used to fit the risk assessment models in this research, a correlation analysis was performed to determine relationships among independent variables. Thus, the variables that were highly correlated (with a correlation coefficient greater than $r=0.5$ ) were found, and only one variable was used in the regression analysis (Hair et al., 1995).

For each respondent, the odds ratios of significant factors were calculated to determine the respondents under high risk of having physical discomfort. Then, those respondents who had higher odds ratios (above $50 \%$ ) were invited to participate in a muscle activity measurement experiment in a classroom-simulated environment, where they performed educational reading and writing tasks on a tablet. The eight respondents who attended this test were divided into two; a test and a control group. Four of them, who were identified by the risk assessment model to be in the high-risk group, were invited to the test group, while the other four, non-risk group, constituted the control group.

Surface electromyogram (a non-invasive device) was utilized to collect muscular activities from six muscle groups; neck, shoulder, upper back, lower back, forearm, and wrist. Analysis of Variance (ANOVA) was carried out to validate and verify the risk assessment model based on the muscular activity data collected.

\section{RESULTS}

According to the Statistical Yearbook (The Ministry of Education of Turkish Republic of Northern Cyprus, Department of Common Services for Education, 2014), there were 18,249 students enrolled in the public and private secondary and high schools of Northern Cyprus at the time of this study. By using the Yamane's formula, the sample size was found to be 391 respondents with $95 \%$ confidence level and 5\% sampling error. 500 questionnaires 
Table 1. Demographics of the respondents $(n=283)$

\begin{tabular}{lcccc}
\hline Variable & Min & Max & Mean & Std. Deviation \\
\hline Age (years) old) & 11 & 20 & 14.05 & 2.18 \\
\hline Height $(\mathrm{m})$ & 1.25 & 1.90 & 1.62 & 0.11 \\
\hline Weight $(\mathrm{kg})$ & 28 & 96 & 55.09 & 13.82 \\
\hline
\end{tabular}

Table 2. Main reason(s) for using a tablet $(n=283)$

\begin{tabular}{ll}
\hline Purpose & Percent of student \\
\hline Communication & $78.09 \%$ \\
\hline Gaming & $73.85 \%$ \\
\hline Watching films/shows & $49.12 \%$ \\
\hline Studying outside school & $46.66 \%$ \\
\hline Studying at school & $26.15 \%$ \\
\hline Internet surfing & $74.91 \%$ \\
\hline Reading & $50.53 \%$ \\
\hline Writing & $34.28 \%$ \\
\hline
\end{tabular}

Table 3. Analysis of the experienced physical discomfort $(n=283)$

\begin{tabular}{lll}
\hline Body Region & Yes & No \\
\hline Neck & $40.28 \%$ & $59.72 \%$ \\
\hline Shoulder (right) & $24.09 \%$ & $75.91 \%$ \\
\hline Shoulder (left) & $16.61 \%$ & $88.39 \%$ \\
\hline Upper back & $39.92 \%$ & $60.08 \%$ \\
\hline Upper arm (right) & $9.89 \%$ & $90.11 \%$ \\
\hline Upper arm (left) & $9.19 \%$ & $90.81 \%$ \\
\hline Lower back & $33.21 \%$ & $66.79 \%$ \\
\hline Forearm (right) & $10.95 \%$ & $89.05 \%$ \\
\hline Forearm (left) & $9.19 \%$ & $90.81 \%$ \\
\hline Wrist (right) & $19.08 \%$ & $80.92 \%$ \\
\hline Wrist (left) & $12.37 \%$ & $87.63 \%$ \\
\hline Hand/fingers (right) & $10.95 \%$ & $89.05 \%$ \\
\hline Hand/fingers (left) & $13.07 \%$ & $88.42 \%$ \\
\hline Hip/Buttocks & $14.29 \%$ & $86.93 \%$ \\
\hline Thigh (right) & $16.26 \%$ & $83.74 \%$ \\
\hline Thigh (left) & $14.84 \%$ & $85.16 \%$ \\
\hline Knee (right) & $16.96 \%$ & $83.04 \%$ \\
\hline Knee (left) & $14.13 \%$ & $85.87 \%$ \\
\hline Lower leg (right) & $13.07 \%$ & $86.93 \%$ \\
\hline Lower leg (left) & $12.37 \%$ & $87.63 \%$
\end{tabular}

were distributed and 406 completed questionnaires were collected; therefore, the response rate was $81 \%$. Among these respondents, 283 students stated that they were using tablet, and/or tablet and desktop, and/or tablet and laptop computers. Thus, all the calculations were made considering this specific focus group of 283 respondents.

The questionnaire results revealed that 156 students (55\%) were female, and the rest were male students. Table 1 illustrates the demographic structure of the respondents. It was observed that 146 students were between 11-13 years old, 119 students were between 14-17 years old, and 18 students were 17 years old and more.

Table 2 shows that $78.09 \%$ of the students prefer using a tablet for communication, $73.85 \%$ for gaming, and $49.12 \%$ for watching films/shows. The least common response to this question was studying at school with only $26.15 \%$.

Table 3 shows that the physical discomforts among students due to tablet-use are intensively experienced at the neck, upper back, lower back, and shoulder regions, respectively.

Correlation analysis was performed to illustrate the impact of tablet-use on different body regions. It was observed that shoulders (both right and left), upper back, and upper arms (both right and left) were significantly affected by different means of tablet-use (Table 4). Among the educational activities, reading was found to affect the shoulders and the upper back, and writing was found to affect the left upper arm. Beyond these, communication, studying outside of school, and internet surfing were also identified to be the other means of tablet activities that affect different body regions. 
Table 4. Body regions significantly affected due to tablet-use $(n=283)$

\begin{tabular}{|c|c|c|c|c|c|}
\hline Body region & Communication & Studying outside school & Internet surfing & Reading & Writing \\
\hline Shoulder (right) & & & $0.126^{*}$ & $0.174^{* *}$ & \\
\hline Shoulder (left) & & & $0.128^{*}$ & $0.141^{*}$ & \\
\hline Upper back & & & & $0.182^{*}$ & \\
\hline Upper arm (right) & $0.133^{\star}$ & $0.118^{*}$ & & & \\
\hline Upper arm (left) & & & & & $0.154^{* *}$ \\
\hline
\end{tabular}

Table 5. Correlation analysis of variables $(n=283, r \geq 0.5)$

\begin{tabular}{lll}
\hline Variable 1 & Variable 2 & Correlation Coefficient \\
\hline Height & Weight & 0.723 \\
\hline Uses Desktop for Communication Purposes & Uses Desktop for Gaming Purposes & 0.524 \\
\hline Uses Desktop for Communication Purposes & Uses Desktop for Watching Films/shows & 0.557 \\
\hline Uses Desktop for Communication Purposes & Uses Desktop for studying outside school & 0.527 \\
\hline Uses Desktop for Communication Purposes & Uses Desktop for Internet surfing & 0.571 \\
\hline Uses Laptop for Communication Purposes & Uses Laptop for Internet surfing & 0.542 \\
\hline Uses Laptop for Internet surfing & Uses Laptop for Communication Purposes & 0.542 \\
\hline Uses Laptop for Internet surfing & Uses Laptop for Watching Films/shows & 0.507 \\
\hline Uses Desktop for Internet surfing & Uses Desktop for Gaming Purposes & 0.514 \\
\hline Uses Desktop for Internet surfing & Uses Desktop for Watching Films/shows & 0.509 \\
\hline Uses Desktop for Internet surfing & Uses Desktop for writing purposes & 0.559 \\
\hline Uses Desktop for writing purposes & Uses Desktop for studying outside school & 0.526 \\
\hline Uses Desktop for writing purposes & Uses Desktop for reading purposes & 0.559 \\
\hline Most preferred location for desktop usage & Cumulative years of usage - desktop & 0.614 \\
\hline Most preferred location for laptop usage & Cumulative years of usage - laptop & 0.663 \\
\hline Ache, pain, discomfort in shoulder (right) & Ache, pain, discomfort in shoulder (left) & 0.554 \\
\hline Ache, pain, discomfort in upper back & Ache, pain, discomfort in lower back & 0.509 \\
\hline Ache, pain, discomfort in forearm (right) & Ache, pain, discomfort in forearm (left) & 0.54 \\
\hline Ache, pain, discomfort in hands/fingers (right) & Ache, pain, discomfort in hands/fingers (left) & 0.604 \\
\hline Ache, pain, discomfort in thigh (right) & Ache, pain, discomfort in lower leg (right) & 0.503 \\
\hline Ache, pain, discomfort in thigh (right) & Ache, pain, discomfort in thigh (left) & 0.77
\end{tabular}

Table 6. Significant risk factors of discomfort experience among tablet-users $(n=283)$

\begin{tabular}{lcccccc}
\hline \multirow{2}{*}{ Predictor } & \multirow{2}{*}{ Coef. } & \multirow{2}{*}{ S. E. Coef. } & \multirow{2}{*}{ Sig. } & \multirow{2}{*}{ Odds Ratio } & \multicolumn{2}{c}{$\mathbf{9 5 \%} \mathbf{~ C l}$} \\
\cline { 5 - 8 } & & & & Lower & Upper \\
\hline Uses Laptop for communication & -0.364 & 0.175 & 0.038 & 0.695 & 0.493 & 0.979 \\
\hline Uses Tablet for watching films/shows & -0.311 & 0.145 & 0.032 & 0.732 & 0.551 & 0.973 \\
\hline Uses Tablet for reading purposes & 0.625 & 0.19 & 0.001 & 1.868 & 1.287 & 2.712 \\
\hline Laptop Feeling Amazement & 0.834 & 0.382 & 0.029 & 2.302 & 1.089 & 4.864 \\
\hline Participant Basketball actively & 0.312 & 0.11 & 0.004 & 1.367 & 1.102 & 1.695 \\
\hline Participant Gymnastics actively & -0.147 & 0.071 & 0.037 & 0.863 & 0.752 & 0.991 \\
\hline
\end{tabular}

In order to avoid the multicollinearity between independent variables used to fit the risk assessment models in this research, another correlation analysis (Table 5) was performed to determine relationships among independent variables. Between the highly correlated variables (with a correlation coefficient greater than $r=0.5$ ), only one variable was used in the multiple regression analysis (Hair et al., 1995).

Logistic regression was used to determine a risk assessment model to determine significant risk factors that contribute to the experience of physical discomfort among tablet-users. The dependent variable was selected to be the experiences of physical discomfort, which is a binary variable (yes/no). Independent variables were considered to be other variables from the questionnaire. Table 6 provides a list of significant risk factors. The mathematical model given below is utilized to calculate the odds ratios of significant factors for each respondent to find out the respondents under high risk of having discomfort.

$$
Y=-0.364 \beta_{1}-0.311 \beta_{2}+0.625 \beta_{3}+0.834 \beta_{4}+0.312 \beta_{5}-0.147 \beta_{6}
$$

where

$$
\beta_{1}=\text { Uses Laptop for communication }
$$

$\beta_{2}=$ Uses Tablet for watching films or TV series 
Table 7. ANOVA results of test and control group respondents

\begin{tabular}{cccccccc}
\hline Test group & $\mathbf{F}$ & P-Value & F critical & Control group & $\mathbf{F}$ & P-Value & F critical \\
\hline 1 & 0.30 & 0.93 & 2.45 & 1 & 0.85 & 0.55 & 2.45 \\
\hline 2 & 0.51 & 0.80 & 2.45 & 2 & 0.24 & 0.96 & 2.45 \\
\hline 3 & 1.70 & 0.16 & 2.45 & 3 & 0.02 & 1.00 & 2.45 \\
\hline 4 & 0.02 & 1.00 & 2.45 & 4 & 0.39 & 0.88 & 2.45 \\
\hline
\end{tabular}

$$
\begin{gathered}
\beta_{3}=\text { Uses Tablet for reading purposes } \\
\beta_{4}=\text { Laptop for feeling amazement } \\
\beta_{5}=\text { Participant in Basketball actively } \\
\beta_{6}=\text { Participant in Gymnastics actively }
\end{gathered}
$$

Odds ratios for each respondent were calculated based on the risk assessment model. Thus, 142 students $(n=283)$ were identified to be in the high-risk group to suffer from discomfort, 40 students were assessed to have discomforts at the upper body, and 30 students were estimated to experience discomforts at all body regions as evaluated by the questionnaire. A test group has been formed with 4 respondents selected from the high-risk group (odds ratios $>50 \%$ ), and a control group has been formed with 4 students from the non-risk group (odds ratios $<50 \%$ ).

ANOVA was applied for each respondent' muscular activity data during tablet-use in a classroom simulated environment to test the hypothesis that mean musculoskeletal strain of the six body regions would not differ for each respondent. The results of both the test and control group (Table 7) implied that there were in actuality significant differences among the six muscle groups for each respondent. Therefore, the hypothesis was rejected, which means that our risk assessment model is verified and validated with the muscle activity measurements.

\section{DISCUSSION}

The use of tablet computers within the classrooms for educational purposes are gaining popularity and importance. However, the physical development of children/adolescents is still in progress. Thus, there was a need for an interpretive analysis of literature as tablet-children-education trilogy has not been thoroughly studied yet. This gap in the literature makes it hard to analyze the negative impacts of tablet-assisted education compared to traditional education. Therefore, we had to determine an assessment model that would identify the significant risk factors to have an effect on physical discomforts experienced during tablet-use for educational purposes.

Together with a comprehensive review of the literature, the main contributions of the current research are the following: It was shown that tablet-assisted education has a significant impact on the students. The research findings have provided that the physical and posture related problems experienced in traditional educational are likely to be experienced in tablet-assisted education as well. This result was also verified by Lin et al. (2015), who showed that pro-longed touch-typing affects the upper extremities and neck. Also, Kingston et al. (2016) pointed out that reading tasks performed using tablet computers affected wrist, elbow, and shoulder.

In order to avoid long term musculoskeletal problems, some studies suggest adding appropriate physical exercises to school programs to reduce or eliminate physical discomfort or pain experienced by children/adolescents. Straker et al. (2009) stated that in the new IT adaptation period, children need to be encouraged to avoid posture and activity monotony, while Fanucchi et al. (2009) pointed out that exercise programs should be added to school programs to reduce or eliminate physical discomfort or pain experienced by children/adolescents. Syazwan et al. (2011) implemented an intervention in the classroom settings of school children to improve the body posture, and provided that discomfort/pain experienced may be reduced via some exercises and awareness on bad body postures.

The deduction associating educational tablet-use and experienced physical discomfort does not necessarily mean that tablet-assisted education will increase musculoskeletal discomfort. After reviewing the literature and working with students in educational settings, the suggestions to avoid physical discomfort during educational activities are the following: Correct, supporting, and adjustable furniture at school; some physical exercises to be performed several times a day under the supervision of a specialist; short but frequent breaks. However, as also underlined by Harris et al. (2005) and Harris (2010), home settings should not be disregarded.

Beyond addressing the impacts of tablet-use for educational purposes, this study shows that students are also engaged with tablets for extra-curricular activities such communication, gaming, watching films/shows, and that the impact of these activities should not be disregarded. 
Furthermore, the results of this comparative review may provide researchers with more reliable references, which can guide future studies. Intervention and follow-up studies in classrooms should be designed to find out the long-term effects of tablet-use.

\section{CONCLUSION}

The purpose of this study was to provide an analysis and comparison of physical discomfort experienced during the emerging tablet-assisted educational activities/environments and during the traditional educational settings, which is widely analyzed in the literature.

The literature review and the analysis of this current research has shown that the impacts of traditional and tablet-assisted education on physical discomfort of students are very similar. Specifically, this study has shown that the physical discomforts among students due to tablet-use are intensively experienced at the neck, upper back, lower back, and shoulder regions, respectively. Moreover, it has been found that of the tablet-assisted educational activities, reading has an effect on the shoulders and the upper back, and writing affects the left upper arm.

The developed risk assessment model has shown that both educational and extra-curricular activities are significant risk factors that have an impact on physical discomfort experienced by the students. Muscular activity analysis has been used to collect data from a control and test group of students during a classroom-simulated environment to test the hypothesis that "mean musculoskeletal strain of the six body regions would not differ for each respondent". ANOVA results implied that there were actually significant differences among the six muscle groups for each respondent. So the hypothesis was rejected, which means that our risk assessment model is verified and validated with the muscle activity measurements.

Therefore, this study not only discusses the findings of the effects of traditional education, but also fills an important gap in the literature with the development of a risk model that determines the impact of tablet-assisted education on students. Thus, a comprehensive comparison of traditional and tablet-assisted education has been achieved as a result of this study.

\section{REFERENCES}

Briggs, A., Straker, L. M., \& Greig A. (2004). Upper quadrant postural changes of school children in response to interaction with different information technologies. Ergonomics, 47(7), $790-819$. doi:10.1080/00140130410001663569

Clinch, J., \& Eccleston, C. (2009). Chronic musculoskeletal pain in children: assessment and management. Rheumatology, kep001. doi:10.1093/rheumatology/kep001

Cornell University Ergonomics Web (CUergo). (1999). Cornell Musculoskeletal Discomfort Questionnaires. Retrieved from http:/ /ergo.human.cornell.edu/ahmsquest.html

Erdinç, O., \& Ekşioğlu, M. (2009a). Student Specific Cornell Musculoskeletal Discomfort Questionnaires (SS-CMDQ) (English Version). Retrieved from http://ergo.human.cornell.edu/ahSSCMDQquest.html.

Erdinç, O., \& Ekşioğlu, M. (2009b). Student Specific Cornell Musculoskeletal Discomfort Questionnaires (SS-CMDQ) (Turkish Version), Retrieved from http://ergo.human.cornell.edu/ahSSCMDQquestTurkish.html

Fanucchi, G. L., Stewart, A., Jordaan, R., \& Becker, P. (2009). Exercise reduces the intensity and prevalence of low back pain in 12-13 year old children: a randomized trial. Australian Journal of Physiotherapy, 55(2), 97-104. doi:10.1016/S0004-9514(09)70039-X

Figueiredo, A. D., \& Afonso, A. P. (2005). Context and learning: A philosophical approach. In Figueiredo, A. D., \& Afonso, A. P. editors. Managing learning in virtual settings: The role of context. Hershey, PA: Idea Group. pp. $1-22$.

Greig, A. M., Straker, L. M., \& Briggs, A. M. (2005). Cervical erector spinae and upper trapezius muscle activity in children using different information technologies. Physiotherapy, 91(2), 119-126. doi:10.1016/j.physio.2004.10.004

Hair Jr., J. F., Anderson, R. E., Tatham, R. L., \& Black, W. C. (1995). Multivariate Data Analysis: With Readings, Fourth ed. Prentice Hall.

Harris, C. (2010). Musculoskeletal outcomes in children using computers: a model representing the relationships between user correlates, computer exposure and musculoskeletal outcomes. Ph.D. Curtin University, School of Physiotherapy.

Harris, C., Straker, L., \& Pollock, C. (2005). Trinidad S., Musculoskeletal outcomes in children using information technology - the need for a specific etiological model. International Journal of Industrial Ergonomics, 35, 131138. doi:10.1016/j.ergon.2004.07.003 
Hashemi, M., Azuzunezhad, M., Najafi, V., \& Nesari, A. J. (2011). What is mobile learning? Challenges and capabilities. Procedia-Social and Behavioral Sciences, 30, 2477-2481. doi:10.1016/j.sbspro.2011.10.483

Hedge, A. (2005). Chapter 9: Kids and computers, Taylor and Francis. In J. Anshel (Ed.) Visual Ergonomics Handbook, e-book ISBN-13: 978-1-56670-682-7, 137-155.

Henderson, S., \& Yeow, J. (2012). iPad in education: A case study of iPad adoption and use in a primary school, System sciences (hicss), 2012 45th Hawaii International Conference on (pp. 78-87), IEEE. doi:10.1109/HICSS.2012.390

Hildebrandt, V. H., Bongers, P. M., Van Dijk, F. J. H., Kemper, H. C. G., \& Dul, J. (2001). Dutch Musculoskeletal Questionnaire: description and basic qualities. Ergonomics, 44(12), 1038-1055. doi:10.1080/00140130110087437

Kim, J. H., Aulck, L., Thamsuwan, O., Bartha, M. C., \& Johnson, P. W. (2014). The effect of key size of touch screen virtual keyboards on productivity, usability, and typing biomechanics. Human factors, 56(7), 1235-1248. doi:10.1177/0018720814531784

Kingston, D. C., Riddell, M. F., McKinnon, C. D., Gallagher, K. M., \& Callaghan, J. P. (2016). Influence of Input Hardware and Work Surface Angle on Upper Limb Posture in a Hybrid Computer Workstation. Human Factors: The Journal of the Human Factors and Ergonomics Society, 58(1), 107-119. doi:10.1177/0018720815607317

Limon, S., Valinsky, L. J., \& Ben-Shalom, Y. (2004). Children at risk: risk factors for low back pain in the elementary school environment. Spine, 29(6), 697-702.

Lin, M. I. B., Hong, R. H., Chang, J. H., \& Ke, X. M. (2015). Usage Position and Virtual Keyboard Design Affect Upper-Body Kinematics, Discomfort, and Usability during Prolonged Tablet Typing. PloS one, 10(12), e0143585. doi:10.1371/journal.pone.0143585

Melanson, D. (2011, October 3). IDC: 18 Million Tablets, 12 Million E-Readers Shipped in 2010. Retrieved from: http:/ /www.engadget.com/2011/03/10/idc-18-million-tablets-12-million-e-readers-shipped-in-2010/.

Mohd Azuan, K., Zailina H., Shamsul B. M. T., Nurul Asyiqin M. A., Mohd Azhar M. N., \& Syazwan Aizat, I. (2010). Neck, upper back and lower back pain and associated risk factors among primary school children. Journal of Applied Sciences, 10, 431-435.

Pelgrum, W. J. (2001). Obstacles to the integration of ICT in education: results from a worldwide educational assessment. Computers \& education, 37(2), 163-178.

Roth-Isigkeit, A., Thyen, U., Stöven, H., Schwarzenberger, J., \& Schmucker, P. (2005). Pain among children and adolescents: restrictions in daily living and triggering factors. Pediatrics, 115(2), e152-e162. doi:10.1542/peds.2004-0682

Sommerich, C. M., Ward, R., Sikdar, K., Payne, J., \& Herman, L. (2007). A survey of high school students with ubiquitous access to tablet PCs. Ergonomics, 50(5), 706-727. doi:10.1080/00140130701194793

Staker, L. M., Maslen, B., Burgess-Limerick, R., \& Pollock, C. (2009). Children have less variable postures and muscle activities when using new electronic information technology. Journal of Electromyography and Kinesiology, 19(2), 132-143, doi:10.1016/j.jelekin.2007.11.011

Staker, L. M., Maslen, B., Burgess-Limerick, R., \& Pollock, C. (2009). Children have less variable postures and muscle activities when using new electronic information technology. Journal of Electromyography and Kinesiology, 19(2), 132-143. doi:10.1016/j.jelekin.2007.11.011

Straker, L., Coleman, J., Skoss, R., Maslen, B. A., Burgess-Limerick, R., \& Pollock, C. M. (2008). A comparison of posture and muscle activity during tablet computer, desktop computer and paper use by young children. Ergonomics, 51(4), 540-555. doi:10.1080/00140130701711000

Syazwan A., Azhar, M. M., Anita, A., Azizan, H., Shaharuddin, M., Hanafiah, J. M., Muhaimin A. A., Nizar A. M., Mohd Rafee, B., Mohd Ibthisham, A., \& Kasani, A. (2011). Poor siting posture and heavy schoolbag as contributors to musculoskeletal pain in children: an ergonomic school education intervention program. Journal of Pain Research, 4(4), 287-296. doi:10.2147/JPR.S22281

Tamim, R. M., Borokhovski, E., Pickup, D., \& Bernard, R. M. (2015). Large-scale, government-supported educational tablet initiatives. Commonwealth of Learning, ISBN 978-1-894975-69-8.

Woo, E. H., White, P., \& Lai, C. W. (2016). Impact of information and communication technology on child health. Journal of pediatrics and child health, 52(6), 590-594. doi:10.1111/jpc.13181

Yamane, T. (1967). Statistics: An Introductory Analysis, 2nd Ed. New York: Harper and Row.

Yan, Z., Hu, L., Chen H., \& Lu, F. (2008). Computer Vision Syndrome: A widely spreading but largely unknown epidemic among computer users. Computers in Human Behavior, 24(5), 2026-2042. doi:10.1016/j.chb.2007.09.004 
Zovkic, M., Vrbanec, T., \& Jasminka, D. (2011). Computer ergonomic of elementary school students. Proceedings of 22nd Central European Conference on Information and Intelligent systems, Varazdin, Croatia, 37-45.

Zunjic, A., Papic, G., Bojovic, B., Matija, L., Slavkovic, G., \& Lukic, P. (2015). The role of ergonomics in the improvement of quality of education. FME Transactions, 43(1), 82-87. doi:10.5937/fmet1501082Z

\section{http://www.ejmste.com}

